E3S Web of Conferences 1, 08003 (2013)

DOI: $10.1051 / \mathrm{e} 3$ sconf/20130108003

(c) Owned by the authors, published by EDP Sciences, 2013

\title{
Novel Approach for the Remediation of Radioactive Cesium Contaminated Soil with nano-Fe/Ca/CaO Dispersion Mixture in Dry Condition
}

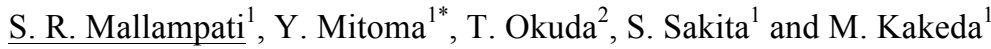 \\ ${ }^{1}$ Department of Environmental Sciences, Faculty of Life and Environmental Sciences, Prefectural University of Hiroshima, \\ 562 Nanatsuka-Cho, Shobara City, Hiroshima 727-0023, JAPAN \\ ${ }^{2}$ Environmental Research and Management Center, Hiroshima University, 1-5-3 Kagamiyama, Higashi-Hiroshima, \\ Hiroshima 739-8513, JAPAN \\ *Corresponding author. Tel./fax: +818247 41748; E-mail addresses: mitomay@pu-hiroshima.ac.jp.
}

\begin{abstract}
Present study, first time we developed a nano- $\mathrm{Fe} / \mathrm{Ca} / \mathrm{CaO}$ dispersion mixture based remediation and volume reduction method of real radioactive cesium contaminated soils. After soil samples treated with $10 \mathrm{wt} \%$ of nano- $\mathrm{Fe} / \mathrm{Ca} / \mathrm{CaO}$ dispersion mixtures, emitting radiation intensity was reduced from $4.00 \mu \mathrm{Sv} / \mathrm{h}$ to $0.95 \mu \mathrm{Sv} / \mathrm{h}$ in non-magnetic fraction soils. While, after treatment, about $30 \mathrm{wt} \%$ magnetic and $70 \mathrm{wt} \%$ nonmagnetic fraction soils were separated, and it's condensed radioactive cesium concentration was about $80 \%$ and $20 \%$, respectively. By this way, cesium contaminated soil volume can be reduced. These preliminary results appear to be very promising and the simple mixing with the addition of nano- $\mathrm{Fe} / \mathrm{Ca} / \mathrm{CaO}$ may be considered potentially applicable for the remediation and separation of radioactive Cs contaminated soil in dry conditions.
\end{abstract}

Key words: Contaminated soil, Nano-Fe/Ca/CaO, Radioactive cesium, Remediation, Volume reduction.

\section{Introduction}

In Japan, the major concern on the radioactive cesium deposition and its soil contamination due to the emission from the Fukushima Daiichi Nuclear Power Plant showed up after a massive quake on March 11, 2011 (Nuclear and Industrial Safety Agency, 2011). The Japan government recent radiation map shows high levels of radioactive cesium in Fukushima and surrounding prefectures. Some spots have levels between 100,000 and 600,000 becquerels per square meter $\left(\mathrm{Bq} / \mathrm{m}^{2}\right)(148,000$ was the standard used for mandatory resettlement after the Chernobyl disaster) (Patel, 2011). According to the Japan science ministry about 8 percent of the country's land has been contaminated with $\mathrm{Cs}^{137}$ levels higher than 10,000 $\mathrm{Bq} / \mathrm{m}^{2}$, a threshold that Japan's science ministry defines as affected by the nuclear accident (Ishizuka, 2011). The soil area around the nuclear power plant in Fukushima has more than $100,000 \mathrm{~Bq} / \mathrm{m}^{2}$ of $\mathrm{Cs}^{137}$. Miyagi and Ibaraki prefectures have levels higher than $25,000 \mathrm{~Bq} / \mathrm{m}^{2}$. Using a conversion factor of $53 \mathrm{~kg}$ of soil per square meter, they calculate that soils in the eastern fraction of Fukushima prefecture exceed the government's safe limit of 2,500 Bq/kg of $\mathrm{Cs}^{137}$ (Yasunari et al., 2011). Soil contamination with radioactive cesium has a long term radiological impact due to its long physical half-life (2 years for $\mathrm{Cs}^{134}$ and 30 years for $\mathrm{Cs}^{137}$ ) and its high biological availability (Staunton and Roubaud 1997). Consumption of agricultural produce contaminated with radiocesium represents the principal route of human exposure to this radionuclide. Therefore, the remediation and volume reduction of radioactive cesium contaminated soil is recognized to be one of the most important problems, which should be solved by taking advantage of suitable technologies. Many diverse methods are used such as solidification, embedding or encapsulation to immobilize the radioactive wastes in a solidified form. Immobilization technique consists of entrapping within a solid matrix i.e cement, cement-based material, polymer or ceramic (Shi and Day, 1996; Plecas et al., 2003). However, among the drawbacks of these processes, the modification of original soil properties, the progressive reduction of the efficiency due to the degradation and/or saturation of reactants, forming of secondary effluents and their treatment for additional cost. Therefore, the treatment under dry and water free conditions should be considered. We have recently shown that the nanometallic $\mathrm{Ca} / \mathrm{CaO} / \mathrm{NaH}_{2} \mathrm{PO}_{4}$ desperation mixture is most effective for cesium immobilization (about 96\%) in soil 
by ball milling treatment in dry condition (Srinivasa Reddy et al., 2012). It is well understood that the most effective measure for immediate relief from radioactive cesium is topsoil removal/separation. We assumed that with nano-Fe/Ca/CaO dispersion mixer by simple mixing/grinding, $\mathrm{Ca} / \mathrm{CaO}$ can make immobile salts with moisture and $\mathrm{CO}_{2}$ in atmosphere, including pozzolanic cement and hydraulic property, cesium would be brought into the immobile $\mathrm{Ca}$ salts. Therefore, the calcium carbonate $\left(\mathrm{CaCO}_{3}\right)$ calcium hydroxide $\mathrm{Ca}(\mathrm{OH})_{2}$ layer in soil surface could be produced, hence the cesium on soil surface can enclosed/bided (Srinivasa Reddy et al., 2012). Further by magnetic separation, encapsulated nano-Fe particles in solidified soil can also be separated with magnetic, by this way radioactive cesium contaminated soil volume can be reduced. Therefore, in present study, we developed a nano- $\mathrm{Fe} / \mathrm{Ca} / \mathrm{CaO}$ dispersion mixture based solidification method to immobilization of radioactive cesium and its separation form real radioactive cesium contaminated soils in Fukushima, Japan.

\section{Materials and Methods}

Initially, the radioactive cesium contaminated surface soil samples were collected in two places in Fukushima prefecture, first one is $15 \mathrm{~km}$ far from nuclear power statin and second one is about $80 \mathrm{~km}$ far from power station, and marked as F1 and F2, both soil samples are having $1 \%$ moisture content and, other physical-chemical properties are similar. While, nano-Fe/Ca/CaO was prepared with $\mathrm{Fe} /$ metallic $\mathrm{Ca} / \mathrm{CaO}$ through mechanochemical process. Granular particles of metallic calcium were purchased from Kishida Chemical Co. Ltd. (99\%, particle size distribution: $2-2.5 \mathrm{~mm}$, surface area: $0.43-0.48 \mathrm{~m}^{2} \mathrm{~g}^{-1}$ ). Similarly, Fe powder (size $0.15 \mathrm{~mm}$ ) was purchased from Kishida Chemical Co. Ltd. $\mathrm{CaO}$ was also commercially obtained. At room temperature under Ar, dry $\mathrm{CaO}\left(825^{\circ} \mathrm{C}\right.$ for $\left.2 \mathrm{~h}\right)$ and dry $\mathrm{Fe} /$ metallic $\mathrm{Ca}$ composition $(\mathrm{Fe} / \mathrm{Ca} / \mathrm{CaO}=2 / 2 / 5)$ were introduced in planetary ball mill (20 pieces SUS, $32 \mathrm{~g} / \mathrm{ball})$. Stirred at $600 \mathrm{rpm}$ for $1 \mathrm{~h}$, samples collected in a glass bottles, Ar gas filled and used. Metallic Ca content to total weight was $2.8 \mathrm{mmol} / \mathrm{g}$ mixture. Radioactive cesium contaminated soil samples were mixed along with dry $10 \mathrm{wt} \%$ of nano-Fe/Ca/CaO (ratio: $1.00 / 0.11$ ) at 150-200 $\mathrm{rpm}$ in a small ceramic tumbling mill $(500 \mathrm{~mL}$ size, without ceramic balls) at room temperature under air for $1 \mathrm{hr}$. After mixing, separated magnetic and non-magnetic fractions. The radioactive cesium $\left(\mathrm{Cs}^{134}\right.$ and $\left.\mathrm{Cs}^{137}\right)$ concentrations in soil samples was measured with high purity germanium detector in gamma-ray spectrometry (SEIKO EG \& G GMX-20P4-70) with standard method. While, radioactive cesium contaminated soils emitting radiation was measured with Geiger-Müller counter from upper $5 \mathrm{~cm}$ distance soil surface. In order to elucidate cesium immobilization/separation mechanisms and verify soil alterations during treatment with nano-Fe/Ca/CaO. Further, synthetically cesium $\left(\mathrm{Cs}^{133}\right)$ contaminated soil was prepared in laboratory, $0.2 \mathrm{~g}$ cesium chloride $\left(\mathrm{CsCl}_{2}\right)$ was dissolved in $5 \mathrm{ml}$ water, next, solutions was thoroughly mixed to $1 \mathrm{~kg}$ of sandy soil having $7 \%$ moisture

(non-polluted,

commercially availablemica/isinglass/fibrolite soil type, produced in Okayama prefecture, Japan) and used. Scanning electron microscopy combined with electron dispersive spectroscopy (SEM-EDS; JEOL, JSM6510A equipped with a $\mathrm{Si}$ (Li) probe at resolution of $138 \mathrm{eV}$ ) microanalysis and semi-quantitative analyses was applied.

\section{Results and Discussion}

Initial measured emitting radiation in contaminated soil was about $4.00 \mu \mathrm{Sv} / \mathrm{h}$ in both (F1 and F2) samples. While, radioactive cesium $\left(\mathrm{Cs}^{134}\right.$ and $\left.\mathrm{Cs}^{137}\right)$ concentrations sum of magnetic and non-magnetic fraction soils was 290,970 and $413,440 \mathrm{~Bq} / \mathrm{kg}$ in $\mathrm{F} 1$ sample, and about 293,170 and $420,600 \mathrm{~Bq} / \mathrm{kg}$ in F2 sample respectively. After soil samples treated with $10 \mathrm{wt} \%$ of nano-Fe/Ca/CaO dispersion mixtures, in magnetic fraction soil continued the high emitting value about 2.9 and $2 \mu \mathrm{Sv} / \mathrm{h}$, while decreased the value about 0.95 and $0.65 \mu \mathrm{Sv} / \mathrm{h}$ in non-magnetic fraction in both soil (F1 and F2) samples. Correspondingly, the concentration of cesium $\left({ }^{134} \mathrm{Cs}\right.$ and $\left.{ }^{137} \mathrm{Cs}\right)$ in non-magnetic fraction soil was reduced, while magnetic fraction soil increased (Fig. 1). After treatment with nano- $\mathrm{Fe} / \mathrm{Ca} / \mathrm{CaO}$, about $30 \mathrm{wt} \%$ magnetic and $70 \mathrm{wt} \%$ of non-magnetic fraction soils was separated by magnetic, and the radioactive cesium concentration was condensed (about $80 \%$ ) in this magnetic fraction soil, while only $20 \%$ remained in nonmagnetic fraction soil (Fig. 1). The SEM images for syntactically prepared Cs contaminated soil before and after grinding are shown in Fig. 2. After blending the Cs contaminated syntactic soil with nano- $\mathrm{Fe} / \mathrm{Ca} / \mathrm{CaO}$ decreased the production and development of the core fractionicles and would be caused the hydration products to coat the aggregates extremely, as shown in Fig. 2b. By SEM EDS maps (Fig. 3) and semi- quantitative analysis, it is possible to observe that the amount of Cs mass and atom percent detectable on soil fractionicle surface decreases after nano-Fe/Ca/CaO treatment. Decreased $\mathrm{Cs}$ mass percent form 0.15 to 0.04 in magnetic fraction, while non-magnetic fraction, $0 \%$ of Cs was observed. The reduction of Cs amount on fractionicle surface is a possible explanation of the increase of immobilization. However, in magnetic fraction slight concentration was observed. Further, schematic representation of possible mechanisms, which may determine the immobilization and separation of radioactive cesium contaminated soils after simple mixing with nano- $\mathrm{Fe} / \mathrm{Ca} / \mathrm{CaO}$ dispersion mixture in dry conditions was shown in Fig. 4. It is possible to assume that when soil is contaminated, Cs is adsorbed onto soil fractionicles through a surface coordination process. When mixing starts, soil fractionicles are subjected to collisions that may promote aggregation in presence of nano- $\mathrm{Fe} / \mathrm{Ca} / \mathrm{CaO}$. This fact probably indicates that a certain amount of Cs entrapped inside new aggregates produced during the nano$\mathrm{Fe} / \mathrm{Ca} / \mathrm{CaO}$ treatment (Fig. 4a). On the other hand, we also assumed that reduction of $\mathrm{Cs}$ would be another possible mechanism in case of nano-Ca addition. The standard redox potential of $\mathrm{Cs}^{+}\left(-3.026 \mathrm{~V}, 25{ }^{\mathrm{O}} \mathrm{C}\right)$ is very 


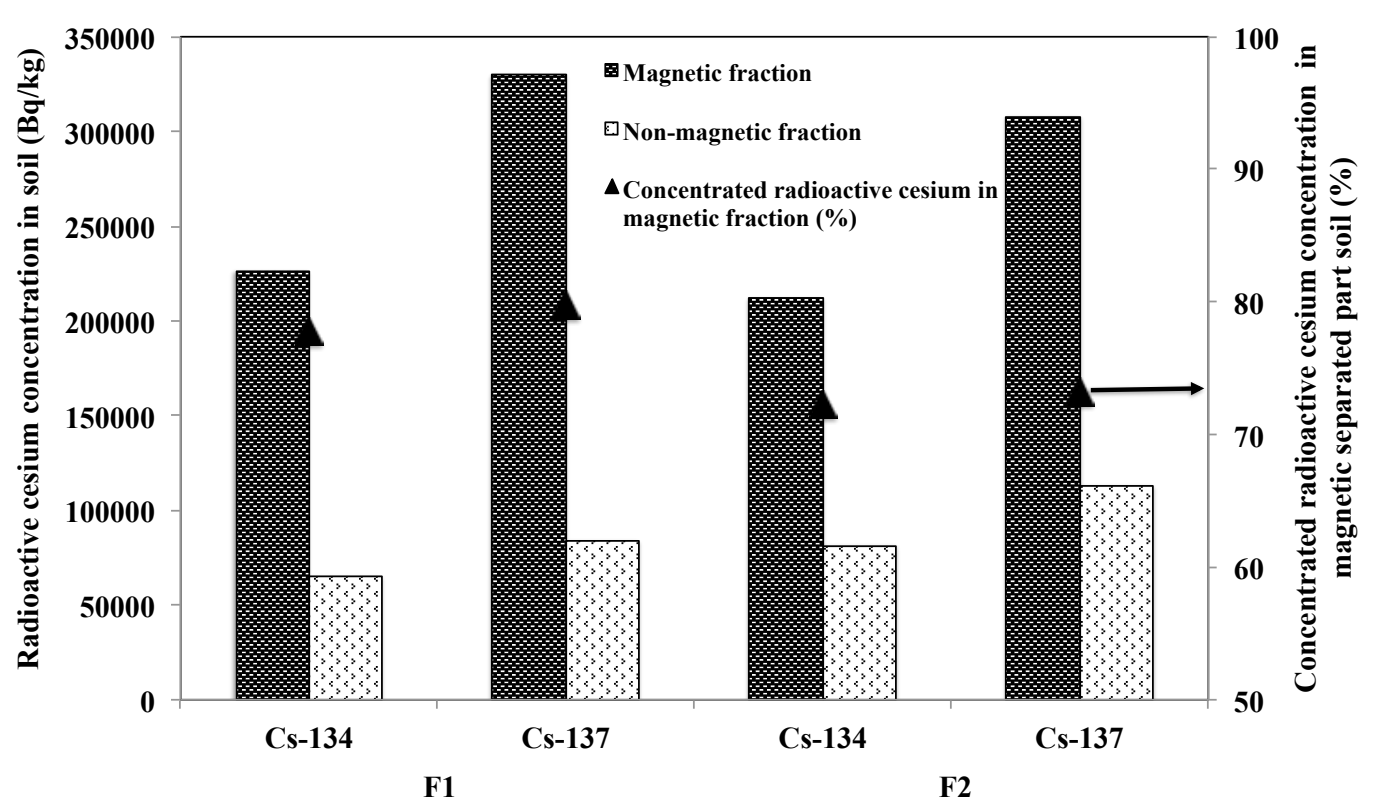

Fig. 1. Radioactive cesium concentrations in magnetic and non-magnetic separated fraction soils after treatment with nano-Fe/Ca/CaO dispersion mixture. (15 km far from nuclear power statin (F1) and about $80 \mathrm{~km}$ far north from power station.

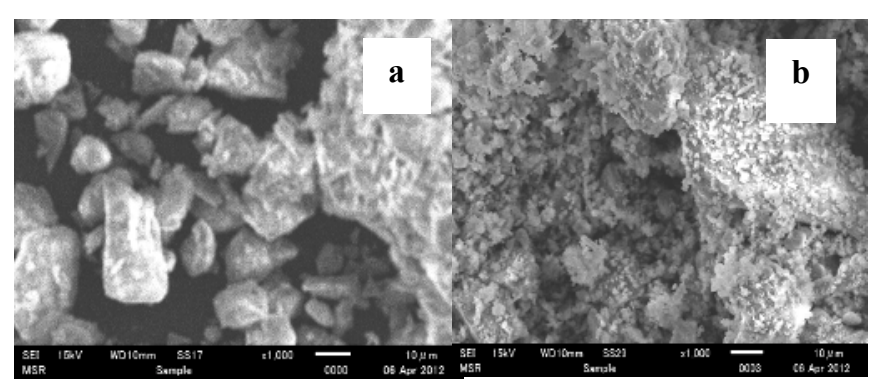

Fig. 2. SEM images at magnitude of 1000 times: (a) Cs contaminated syntactic soil before treatment; (b) after mixing Cs contaminated syntactic soil with nano- $\mathrm{Fe} / \mathrm{Ca} / \mathrm{CaO}$.

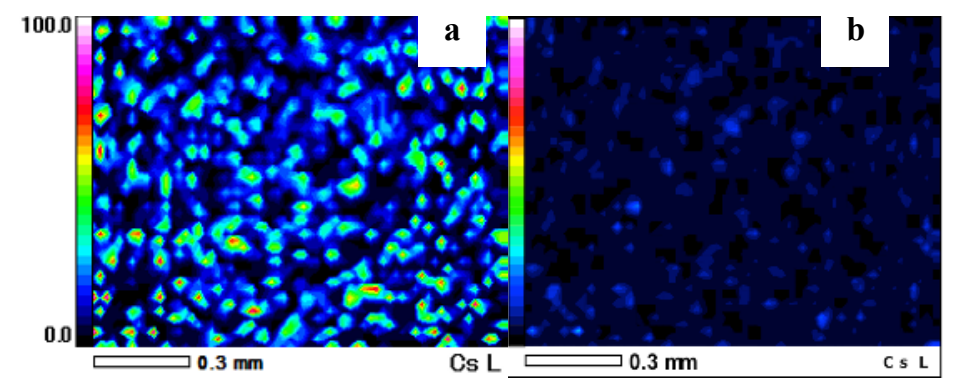

Fig. 3. SEM EDS Cs element maps (a) before treatment and (b) after treatment (non-magnetic separated fraction

close to that of $\mathrm{Ca}^{2+}\left(-2.868 \mathrm{~V}, 25{ }^{\mathrm{O}} \mathrm{C}\right)$, and thus, the removal of $\mathrm{Cs}^{+}$ions by nano $\mathrm{Ca}$ is due to sorption/replacement with $\mathrm{Ca}^{2+}$. Cs either reduced at the nano-Fe $/ \mathrm{Ca} / \mathrm{CaO}$ surface or directly adsorbed to the surface where they are rendered immobile. On the other hand, nano-Fe/Ca/ $/ \mathrm{PO}_{4}$ on the surface of soil can enclosed/bind with the $\mathrm{Cs}$ in the presence of moisture due to its electron sources and the $\mathrm{CaCO}_{3} / \mathrm{Ca}(\mathrm{OH})_{2}$ layer in soil surface could be produced with them (Fig. 4a). Further by magnetic separation, encapsulated nano-Fe fractionicles in solidified soil can also be separated, by this way contaminated soil volume can be reduced (Fig. 4b).

\section{Conclusions}

Present study, first time we developed a nano-Fe/Ca/CaO dispersion mixture based remediation and volume reduction method of real radioactive cesium contaminated soils in Fukushima. After soil samples 


\section{a: Treatment}

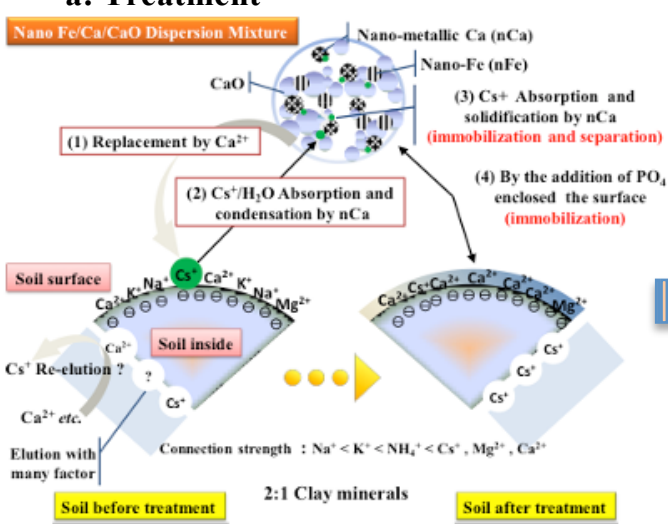

b: Separation

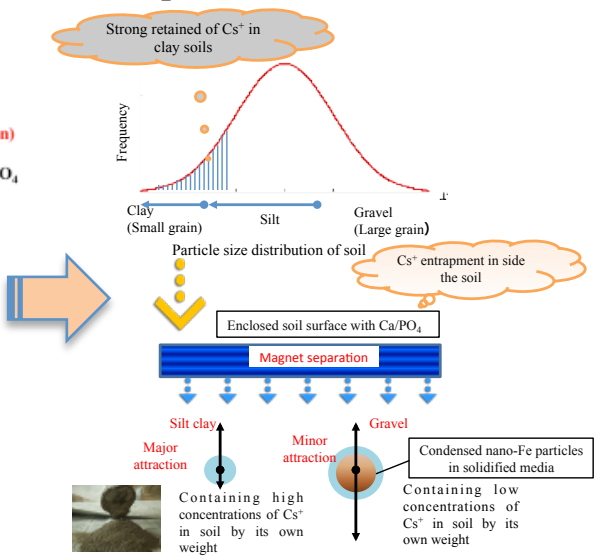

Fig. 4. Schematic representation of possible mechanisms, which may determine the remediation, and separation of radioactive cesium contaminated soils after simple mixing in dry conditions: (a) Treatment and (b) separation.

treated with $10 \mathrm{wt} \%$ of nano-Fe $/ \mathrm{Ca} / \mathrm{CaO}$ dispersion mixtures, in non-magnetic fraction soil emitting radiation intensity was reduced from $4 \mu \mathrm{Sv} / \mathrm{h}$ to $0.95 \mu \mathrm{Sv} / \mathrm{h}$. While, after treatment, about $30 \mathrm{wt} \%$ magnetic and $70 \mathrm{wt} \%$ of non-magnetic fraction soils was separated, and the condensed radioactive cesium concentration was about $80 \%$ and $20 \%$ in magnetic and non-magnetic fraction soils respectively. By this way, cesium contaminated soil volume can be reduced. Thus, we anticipated, the simple mixing technique with the addition of nano-Fe/Ca/CaO may be considered potentially applicable for the remediation and separation of radioactive cesium contaminated soil in dry conditions.

\section{Acknowledgements}

Authors thankful to New Energy and Industrial Technology Development Organization (NEDO) Program (Project ID: 09B35003a)" for providing financial support for this study.

\section{References}

Ishizuka, H. Cesium from Fukushima plant fell all over Japan. The Asahi Shimbun, November 26, 2011. http://ajw.asahi.com/article/0311disaster/fukushima/ AJ20111126000.

Nuclear and Industrial Safety Agency (2011). Available at: http://www.nisa.meti.go.jp/ english/files/en20110321-1.pdf. March 20, 2011.
Patel P. Post-Fukushima Radiation Mapped: Cesium in soil a problem for agriculture. IEEE Spectrum 2011. $1-2$.

(http://spectrum.ieee.org/energy/environment/postfu kushima-radiationano-metallic apped/1)

Plecas IB, Pavlovic RS, Pavlovic SD. Leaching of ${ }^{60} \mathrm{Co}$ and ${ }^{137} \mathrm{Cs}$ from spent ion exchange resins in cementbentonite clay matrix. Bulletin of Materials Science2003; 26:699- 701, 2003.

Shi C, Day RL. Alkali-slag cements for the solidification of radioactive wastes, in: Gilliam, Wiles (Eds.), Stabilization and Solidification of Hazardous, Radioactive, and Mixed Wastes, vol. 1240, American Society for Testing and Materials, ASTM STP, Philadelphia, USA, 1996, pp. 163-173.

Srinivasa Reddy M, Mitoma Y, Okuda T, Sakita S, Kakeda M. High immobilization of soil cesium using ball milling with nano-metallic $\mathrm{Ca} / \mathrm{CaO} / \mathrm{NaH} 2 \mathrm{PO} 4$ : implications for the remediation of radioactive soils. Environmental Chemistry Letters 2012; DOI: 10.1007/s10311-012-0357-3.

Staunton S, Roubaud M., Adsorption of $137 \mathrm{Cs}$ on montmorillonite and illite: effect of charge compensating cation, ionic strength, concentration of Cs, K and fulvic acid. Clay and Clay Minerals 1997; 45:251-260.

Yasunari TJ, Stohl A, Hayano RS, Burkhart JF, Eckhardt S, Yasunari T. Cesium137 deposition and contamination of Japanese soils due to the Fukushima nuclear accident. PNAS 2011; 108:19530-19534. 